\title{
Analysis on Construction of Ideological Safety Pre- Alarm Capacity in Colleges
}

\author{
Li Chunyan, Zhang Zilong \\ School of Marxism, Hubei University of Chinese Medicine \\ Wuhan, Hubei 430065 \\ CPC Publicity Department, Hubei University of Chinese Medicine \\ Wuhan, Hubei 430065
}

\begin{abstract}
The ideological safety pre-alarm in colleges mainly includes the collection, sorting, analysis and judgment of safety intelligence, as well as the construction of emergency pre-alarm mechanism and guarantee system. In light of the hard evaluation and promotion as well as other issues faced by the current ideological safety pre-alarm work in colleges, it is applicable to build ideological safety pre-alarm system in colleges and vigorously promote the alarm source distinguishing and searching capacity, alarm sign analysis and evaluation capacity, alarm situation research and judgment capacity, emergency prealarm mechanism's operation capacity and the safety pre-alarm system's guarantee capacity thus forming the synergistic effect of supervision, prediction, forecast, pre-alarm and fast reaction, and promoting the improvement of the overall ideological prealarm capacity in colleges.
\end{abstract}

Keywords-Colleges; ideology; safety pre-alarm; capacity building

\section{INTRODUCTION}

Ideological safety refers that the state-dominant ideological system is free of threat and dangers and can maintain the normal survival and development, thus showing a state of relative stability, order and harmony. It is an important component and essential embodiment of national safety. The ideological safety pre-alarm capacity in colleges refers to the administrative capacity or administrative management capacity of collages as a social subsystem [1], of which it guarantees to take the leading role of mainstream ideology as the direction, and then to search, research and judge and alarm the threats that may endanger the leading force, cohesion and control force of the mainstream ideology, and meanwhile, to put forward solutions. With respect to the field of ideology, colleges have two big characteristics due to their own particularities: Firstly, they are more sensitive to the ideological trend changes in the field of ideology; Secondly, they have more power to influence the formation and spreading of social ideological trend. Either the national ideological safety threats or the social and regional ideological safety threats will exert different degrees of negative influence on colleges, and induce ideological safety crisis on campus. At present, along with the further in-depth development of globalization, marketization and network orientation, as well as the social structure transformation period we faced at home currently, various internal and external

This article is the periodic research achievement of the teaching reform project of Hubei Province in 2016, i.e., "the Education Language System Innovation and Practice Research of Ideological and Political Course in Colleges under the Perspective of Synergy Theory” (Project No: 2016331). factors are mutually mingled, so the potential threats in the field of ideology in colleges shall not be neglected. In light of these threats, and centering on the emphasis stated by Comrade $\mathrm{Xi}$ Jinping, i.e., "reinforcing thought guidance, and firmly seizing the leadership authority of ideology work in collages" [2], the academic circle has conducted lots of research, and put forward some good solutions and suggestions. But few people are concerned how to improve the validity and reliability of ideological safety pre-alarm from the perspective of capacity building.

\section{PERFECT INFORMATION INTELLIGENCE NETWORK AND PROMOTE ALARM SOURCE PRE-CONTROL CAPACITY}

The essential starting point for the entire safety pre-alarm system is to search the alarm source of mainstream ideology in colleges. The ideological safety threats in colleges can be divided into three types: The first one is exogenous alarm source, which is mainly from the permeation of western culture. The second one is endogenous alarm source, which is mainly from the impact of anomic postmodern thought incurred by the social structure transformation at home. The third one is multifocal alarm source, which means the threats of domestic affairs and foreign affairs are involved based on the single alarm source. Through such division, people will pay more attention to the macro factors of ideological safety in colleges rather than only focusing on the micro-factors on campus; on the other hand, it can also be beneficial to the better combination of daily monitoring and crisis pre-alarm. In reality, the relation between various alarm sources for the ideological safety in colleges is intimate, showing the characteristics of bad predictability, long risk existence, the co-existence of various risks, and intercross. Thus, the results will not be realized through the single pre-alarm for a certain aspect. The judgment capacity for complicated alarm sources is the foundation of ideological safety pre-alarm in colleges.

The detailed approaches for improving the alarm source pre-control capacity are as follows: The first one is to utilize the messenger mechanism to extend the intelligence information network to the end of students as well as teaching and administrative staff groups. The second one is to play the advantages of the party committee, each party committee branch, the general party branch, the main force directly subordinated to the party branch and the relevant functional 
departments to effectively improve the capacity to find unstable factors, thus pointedly putting forward improvement measures. The third one is to focus on the trends of the campus network and the new media public opinions, and pointedly place emphasis on the public opinions about social hot spots and difficult issues. The fourth one is to utilize the full-time and part-time instructor teams to build social psychological pre-alarm system and implement psychological counseling, then timely seize the ideological trends of teachers, students and employees through the psychological health network involving teachers and students. The fifth one is to fully play the role of petition letter, and then pointedly conduct intelligence troubleshooting and collection through holding forum, questionnaire survey, the president's mailbox and other channels.

\section{PERFECT PUBliC OPINION ANALYSIS SYSTEM AND IMPROVE ALARM SIGN EVALUATION CAPACITY}

As the external expression of alarm source, the alarm sign is the sign for the occurrence of ideology safety alarm situation in colleges. The main objective for the ideology safety prealarm in colleges is to evaluate the alarm sign index, and ensure the future trend of alarm sign, and only when conducting correct evaluation and analysis on various anticipatory alarm signs of ideology safety crisis in colleges can different alarm situations be judged, and then the validity and credibility of pre-alarm information be improved. The famous "Hein Rules" point out that: Behind each serious accident, there must be 29 minor accidents, 300 abortive signs and 1,000 accident potentials. However, to eliminate one serious accident, it is requested to keenly and timely find these accident signs and hidden dangers, and meanwhile, decisively adopt measures for control or elimination [3].

The detailed promotion approaches for the alarm sign evaluation capacity are as follows: The first one is to make sequencing consideration towards the generation process of various alarm signs, and this is the precondition and foundation of evaluating the alarm sign. In the big data era, if no scientific methods or technical means are used to collect, analyze and study the relevant data of alarm signs, all management system and the strategy implementation related to ideological safety in colleges will be stopped at the theoretical layer. Then no reliable signs can be found when crisis occurs. The second one is to distinguish the route generating the alarm sign to evaluate its possibility to become a real alarm situation. Then list out the possible alarm signs in each field as well as the possible occurrence time of alarm signs, thus cultivating the sensibility and perceptivity of subjects concerned towards alarm sign. The third one is starting from the principle of "party committee leadership, scientific division of labor, and collective responsibility" to define the corresponding responsibilities in the generation process of alarm sign, and strive to allocate responsibilities to each person. Then make the responsible personnel understand the importance of finding and evaluating the alarm sign through training. The fourth one is to formulate periodic inspection, detection and report system in each field of colleges as per the characteristics thereof to timely find out the alarm signs and get ready ahead of time. In case of finding the threat sign in any field of ideological safety in colleges, enough attention is requested and it must be eliminated at full steam. If this fails, it is requested to timely evaluate the progress and endangering degree of the transformation from alarm sign to alarm situation.

\section{BUILD EVALUATION INDEX SYSTEM AND IMPROVE ALARM SITUATION RESEARCH \& JUDGEMENT CAPACITY}

The ideological safety alarm situation in colleges refers to the abnormal situation departing from norms occurred in the ideology field in the process of normal operation and development. For instance, ideological mass disturbances in colleges, bad comments of teachers and students in public occasions, wrong orientation of news media on campus, loss of leadership, speaking right and control right of mainstream ideology in the campus network and serious influence on ideology safety of campus network, all of the above contents can explain that the alarm situation of ideological safety in colleges has occurred. The alarm situation research and judgment capacity refers to the capacity to research and judge the risk degree of abnormal situation of ideological safety in colleges, and such research and judgment shall reflect the threaten degree that may be caused by the alarm situation, so as to decide on which type of pre-arranged plan shall be started. In the process of improving such research and judgment capacity the alarm situation is not static, so it cannot be eliminated through repression. Besides, the research and judgment of alarm situation evaluation are not ossified. It is better to be regarded as an evolution signal in the dynamic process, thus the research and judgement which can realize continuous tracking, flexibility and mobility are required.

The detailed promotion approaches for the alarm sign research and judgment capacity are as follows: The first one is to build the alarm situation pre-alarm index for ideological safety crisis in colleges. It is requested to set the ideological safety index system as per the characteristics of teachers and students, and then confirm the pre-alarm range and threshold value of each index under the principle of systematicness, sensitivity, independence, and dynamics. With respect to the major crisis, it is also requested to establish emergency management and decision-making mechanism, and adopt emergency measures to timely publish public opinions, ensure safety and properly handle the follow-up resettlement. The second one is to set the upper and lower threshold values of safety alert and define the ideological crisis' level. Then divide alarm signs into different levels (from low to high) as per the degree of influence that is about to be caused by the crisis, coverage, severity degree, development conditions, emergency degree and other factors. Meanwhile, link the corresponding disposal plan as per different evaluation levels. The third one is to utilize talent resources in colleges, play the role of "think tank", and establish alarm situation research and judgment expert consulting mechanism. Especially when evaluating major ideological safety crisis, it is requested to fully consider the evaluation report provided by the relevant experts. 


\section{PROTOCOL SCIENTIFIC WORKING MECHANISM AND IMPROVE OPERATIONAL CAPACITY OF EMERGENCY PRE- ALARM}

As a tool and means to realize the pre-alarm objective, the pre-alarm working mechanism is a systematic engineering, and also a detailed operation mode to coordinate the relations between all parts, so as to exert a better function. But at present, colleges have some dilemmas in promoting the operation capacity of ideological safety pre-alarm mechanism. Firstly, the information management system of ideological safety is not sound enough; the confirmation of pre-alarm index, the alarm sign analysis. The determination of pre-alarm index, alarm sign analysis and alarm situation research and judgment shall be based on the rich information and data, including both realtime information and data and the historical experience data. However, the data and information collection cannot meet the demand at present; Secondly, there is no expert team that can perfect the ideological safety pre-alarm in colleges; thirdly, there is an absence of management institution for ideological safety pre-alarm in colleges.

The detailed promotion approaches for the emergency prealarm operation capacity are as follows: The first one is to start the emergency headquarters of ideological safety when alarm situation occurs, and then cope with the alarm situation as per scientific working mechanism. The emergency headquarters of ideological safety in colleges shall build various systems, including intelligence collection, information recording, and archive management and information feedback. On one hand, the public opinion in colleges shall be researched and judged to define the authenticity and nature thereof, on the other hand, the threaten degree shall be judged to predict the development trend [4]. The second one is to build the scientific analysis system of ideological threat in colleges [5]. Scientifically confirm the index influencing and triggering the ideological safety in colleges. Then analyze, research and judge the alarm source, sign and situation of ideological safety in colleges to divide alarm levels, based on which the corresponding handling plan will be formulated and the appropriate modes will be adopted for internal and external publishing. The third one is to promote the full coverage of ideological safety prealarm in colleges, and then improve the professional assessment group of crisis pre-alarm to periodically analyze and evaluate the risk degree of ideological safety in colleges, and perfect the sharing capacity of ideological intelligence information. For different functional departments, the different levels of intelligence information in a relevant department or a certain field can be shared and mutually exchanged as per different submission range and handling methods. The fourth one is to perfect the publishing capacity of ideological prealarm decision-making in colleges.

\section{PERFECT GUARANTEE SYSTEM AND IMPROVE THE GUARANTEE CAPACITY OF EMERGENCY PRE-ALARM}

The guarantee system of ideological safety pre-alarm in colleges includes the system, organization, talent, technology, fund, publicity and other aspects. The first one is system guarantee, i.e., perfecting various regulations and systems of ideological safety pre-alarm in colleges to ensure the smooth implementation of each work. To ensure that the actual operation have regulations to abide by, it is requested to pointedly reinforce the system construction of ideological safety pre-alarm in colleges as per the relevant laws and regulations, thus striving to make the ideological safety prealarm in colleges move towards systematism, standardization and scientification. The second one is to further perfect the organizational system coping with the ideological crisis and reinforce the organizational guarantee. This plays a dominant role in improving ideological safety pre-alarm capacity and implementing organization function. Through organizational construction, the upward and downward linkage as well as the left and right linkage can be realized in the working field of ideological safety in colleges, and no work debt will be left. The third one is talent guarantee. It is requested to cultivate and maintain ideological safety operators with strong capacity, fast reaction, and strong political sensibility. Meanwhile the construction of think tank is also requested. The fourth one is technical guarantee, which can ensure the application of advanced big data technology, information statistics technology and other high-tech means. In colleges, ideology is able to hide in in various cultural activities "Where the cultures are integrated and surpass the politics to become the most important influence factor in reality, the strong political nature of ideology seems to be weakened [6]." So the form of ideological safety threats in colleges is more complicated. The technical guarantee is especially needed in the network space of information era to make a good fight. The fifth one is fund guarantee. The various expenditures of ideological safety prealarm in colleges shall be listed into the annual budget, and it is requested to ensure a full allocation to improve the fund using efficiency, etc. The sixth one is to enhance the publicity strength of ideological safety in colleges, and create the idea of "safety pre-alarm". "Since it is the environment that creates people, the mode that conforms to human nature shall be used to create the environment" [7]. Make all teachers and students understand the importance and necessity of ideological safety in colleges through propaganda and guidance, thus improving their pre-alarm ability of ideological safety.

\section{CONCLUSION}

The basic principle of ideological safety pre-alarm in colleges is that the relevant responsibility subjects list out the risk factors that may cause the occurrence of ideological crisis in colleges within a certain range, and establish an index system to ensure which kind of situation may cause ideological safety crisis to monitor the various factors that may cause the ideological safety crisis in colleges. Then the relevant responsibility subjects shall provide different levels of prealarm signals and solutions as per the changes of various factors, so as to realize the pre-prevention of ideological safety crisis in colleges. Generally speaking, the ideological safety pre-alarm capacity in colleges includes the collection, sorting, analysis, research and judgment, pre-alarm, and guarantee of ideological safety intelligence in colleges. The promotion in the aforementioned capacities plays a fundamental and meaningful role in ensuring the ideological safety in colleges. 


\section{ACKNOWLEDGMENT}

The First Author: Li Chunyan (1976- ), who is female and an associate professor in School of Marxism, Hubei University of Chinese Medicine, mainly studies ideological safety and education.

Corresponding Author: Zhang Zilong (1964- ), who is male and a professor, as well as the member of the Standing Committee for Hubei University of Chinese Medicine, and the Minister of Propaganda Department, mainly studies the higher education of traditional Chinese medicine, the party construction and the ideological and political education.

\section{REFERENCES}

[1] Shi Yunxia. Ideology Safety Issue in the Development of Contemporary China Cultural Development [J]. Research on Socialism with Chinese Characteristics, 2012 (2).

[2] Xi Jinping. Adhering to the Thought Guidance of Morality Education, and Reinforcing the Improvement of Party Construction in Colleges [N], People's Daily, 2014-12-30 (1).

[3] Yang Yongjun. Social Public Opinion Pre-alarm and Control [M]. People's Publishing House, 2015 Edition, P227.

[4] Alexis de Tocqueville. Democracy in America[M]. New York:Doubleday, 1969.

[5] John Mearsheimer. Why We Will Soon Miss the Cole War[EB/OL].http://teachingamericanhistory.org/library/document/whywe-will-soon-miss-the-cold-war/,2016-07-14.

[6] Hou Huiqin. Foreign Marxism Ideology Research Work Assessment [M] Beijing: China Social Sciences Press, 2015, P434.

[7] Karl Marx and Frederick Engels (Volume I) [M]. Beijing: People's Publishing House, 1995, P335. 